\title{
Research on the Development Trend of Chinese Traditional Music Art from the Perspectives of Aesthetic and Historical Culture
}

\author{
Huihua Liu ${ }^{1}$ \\ ${ }^{1}$ Feixian Campus ,Linyi University ,Shandong, China
}

\begin{abstract}
In this paper, we conduct research on the development trend of Chinese traditional music art from the perspectives of aesthetic and historical culture. In the ancient Chinese aesthetic tradition, "peace" music aesthetic of music practice has the extremely important influence, not only affect the music creation, performance, appreciation that also affect the music form and content, social function, etc. "peace" as beauty is the core of the ancient music esthetics thought, so to speak. Chinese music culture while constantly in the long course of history, the Chinese music culture of different nations, but as a precocious and has a long history of nation, he has a great ability, that is both absorb different music culture, and unified as the relatively stable whole music culture and maintain their own basic features, and distinguish it from other music culture.
\end{abstract}

Keywords- Development Trend. Traditional Music Art, Aesthetic Angle, Historical Culture.

\section{Introduction}

Music the development of the Chinese nation has gone through a journey of thousands of years of the time, the music in constant collision and fusion, the improvement and development, finally formed today music prosperous situation in our country, this article mainly before the modern times of China, the paper briefly summarizes the development of music, in order to help them better understand and learn the music of our country from the primary perspectives of aesthetic and historical culture.

The emergence and development of any art genre or form, is carried out along the need and possible rules. Since the formation and development, and recognized by society, must be made unique artistic contribution for the society and history as has its unique social value. At the same time, any genre of art or art form, and is in accordance with the law of evolution of the movement [1-2].

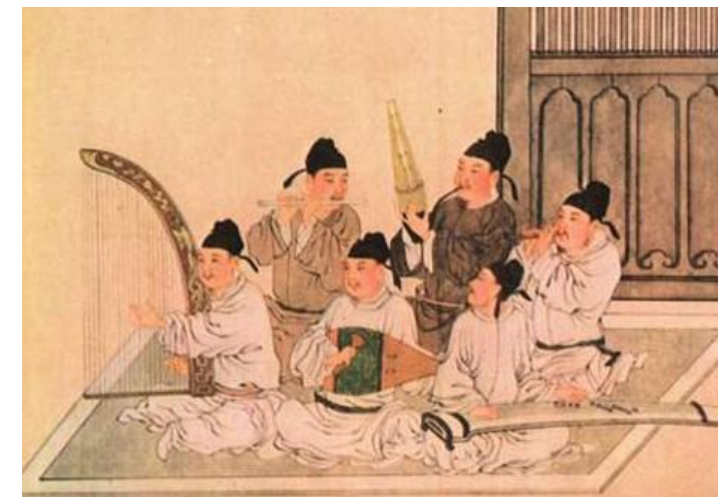

Figure 1. The Chinese Traditional Music Art Forms

According to the literature review, the connotation and characteristics of Chinese traditional music could be generally summarized as the follows. (1) Chinese traditional music is a kind of special music form of the Chinese nation, the use of the technique is unique to our nation, it and people's daily life closely together, from the folk. The authority of the approval according to most of scholars, Chinese traditional music can be roughly divided into folk music, dance, music, hip-hop music, opera music, instrumental music and music, buddhist music, Taoism music, ritual music. (2) Traditional Chinese music is not the pure music phenomenon, and it is a long-term accumulation in the development of a country music history, are at the mercy of the special social life and production mode and influence of performance out of the tenacious vitality. Chinese traditional music has positive and the negative two aspect of that effect, in other words, the properties of the Chinese traditional music has two kinds of the inheritance and basic 
habitual. Continuity of traditional music will exert positive effects on social development, and has a negative effect of traditional music is mostly left over from history that do not adapt to modern social life. In this paper, we conduct research on the development trend of Chinese traditional music art from the perspectives of aesthetic and historical culture.

\section{The Proposed Methodology}

The Properties of the Traditional music. Appreciate the music is the highest stage of the whole music activities, its main purpose is to feel beauty with accept edification of beauty, which in turn to appreciate beauty to create beauty and this is closely linked with people's aesthetic view. People only think of beautiful things to them, just from the bottom of my heart to love it, love it and accept it.

The living condition of the traditional music resources namely traditional music culture in today's living ecology, it by its unique artistic form, is rooted in the folk historical and cultural soil, play an important role in people's social life. Ethnomusicology methodology is always one of the academic research frontiers however, how to build a theory system in the field is a new academic requirement. Due to the hidden in the folk traditional music, basically in a state of die and it mainly displays the following several aspects. (1) In minority nationality traditional culture, as the main functions of the traditional music including knowledge teaching, moral education as entertainment and so on. But now these functions have been swallowed by the tide of social economy. (2) Traditional music. Still some argue that traditional music is just some vulgar, backward and difficulty on the hall of the great music form. (3) Former national traditional music, mainly himself sing to hear, but now mostly sing to listen to others and the social and economic development in national regions and the modern education to implement such a backdrop, the changes in the way the spread of traditional music.
When we will be the research object locking in a particular culture area, time and space coordinates is the primary factor. As a historical culture profound ancient civilization, China has several thousand years of cultural tradition, if to know the culture of the music style as we must focus on the historical background, from which it is in native concept of cognitive mode, and the overall environment and the cultural significance of music behavior. From the diachronic and the synchronic, regional, social, concept, behavior, interactive relationship between individual, sounds of thinking as is constitute the basic theory of time-space coordinate of factors [3-4].

For thousands of years, the development of Chinese music to show the Chinese culture and the different national cultures blend, blend of big tradition and small tradition, the mainstream culture and grassroots culture, showing the great powers of China's meteorological and cultural self-confidence. Many of foreign musical instruments, such as QuXiang pipa, hichiriki, suona, dulcimer, premiere, etc., in the long historical development process is absorbed by the Chinese nation, as has the Chinese traditional instrumental music part of the music aesthetic characteristics. During the Ming and Qing dynasties has the typical characteristic of Chinese traditional art of opera, in spoke in different areas of the harmony that eventually produced a "Chinese" of Beijing Opera. At this time of Chinese music culture began to contact with the western music culture, modern appeared after the wider collision, absorption and fusion that show the openness of the Chinese traditional music.

The Music Aesthetic. The contemporary research of music aesthetics in China, for music creation and music appreciation of aesthetics to explore more deeply, and to the study of aesthetics of music performance, is relatively weak. Especially in the study of music performance esthetics, mainly above in music performance practice, to the general introduction of the theory of western music aesthetics, translation, sorting, introduction, for western 
music aesthetics research lack of systematic and deep going. Work of these scholars and related thesis will research focused on the study of the specific problems in music performance art, such as the second creation of the music performance, music and performing arts, the individuality and commonness, style and genre, psychological problems such as the general and ordinary idea of playing and visual expression.

Traditional Chinese music esthetics thought its main body is subject to the ritual, emphasis on the relationship between music and general society politics, ethics, respect teachers entertainment, true, the features are subject to the good is the Confucianism, such as its local heavy softly, the pursuit of "voice", emphasis on the clarification of mind, to entertain themselves, such as general regimen is the buddhist Taoist, its aesthetic standards for peaceful and serene beauty is common.

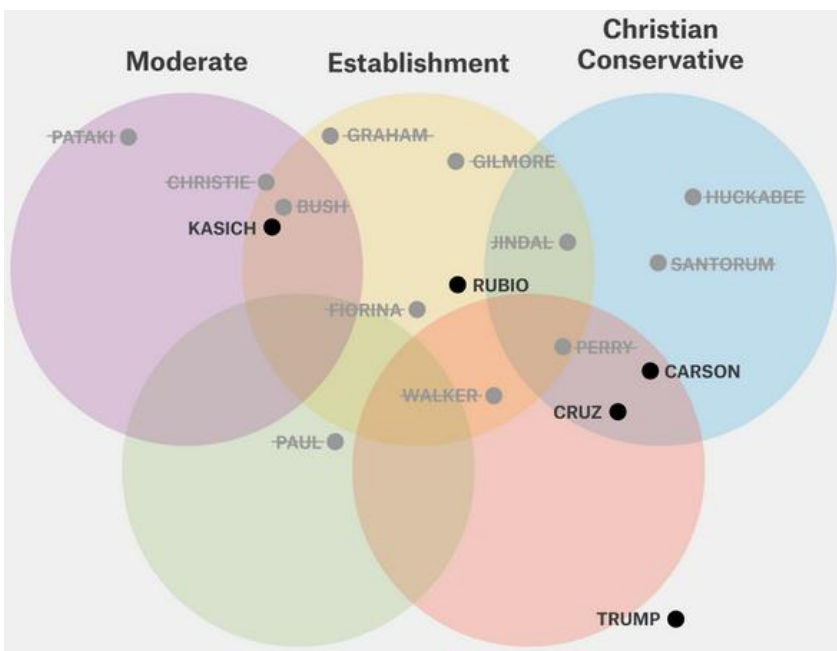

Figure 2. The Perspectives of Music Aesthetic

If these ideas, concepts and viewpoints of historical context and cultural context has not been clear in advance and effective clarification, as the system construction of credibility and convincing will be discounted. In other words, it should be for each kind of idea or of the specific historical context in each category behind to the essence of the music aesthetic issue related to get more thoroughly and in the place of understanding and grasp. Music creation activity of the two aspects as should be uniform, without doubt in regard of music performing arts at the same time, inevitably hit on the component elements of music creation and listen to enjoy, such as the composer and the audience, such as in the composition of music melody, harmony, texture, rhythm, mode, tonality, and many other factors.

In other words, this paper also absorbed music morphology theory, to ensure the accuracy of the ontology research on the western music performing arts and validity, and at the same time, the music performance art as a cultural existence that must correspond to different people, and then applying the viewpoints of culture, namely through the analysis of some kind of cultural phenomenon, this paper tries to probe into general culture behind something deeper. Hegel's music aesthetics, Schopenhauer's philosophy of art, the Hans Pavlik formalism aesthetics evaluation again, the substance of Liszt title music aesthetics, the opera reform and its theoretical premise the aesthetic intuition and the dialectical relationship between historical knowledge and music phenomenological analysis of the problem.

The Music Culture. The diversity of the world music is determined by the national music, that is to say, the world's ethnic diversity determines the diversity of the world music. No culture under the constraint of a national traits and there is not absolute from the foundations of national music [5].

How to protect cultural diversity in the music world, this is a question worth thinking about as just my personal opinion, "world music" in protection of multicultural work success, is mainly decided to countries around the world and regional governments attitude toward the work. In the collection, the protection on the specific operation of traditional music, some problems are worthy. For example, the music workers to collect other ethnic music that often use their familiar object notation to record the collection. A losing national cultural tradition is sad which is 
also difficult to obtain the long-term development. Standing in the perspective of a nation or stand in the perspective of the mankind, any traditional music culture of the nation in the world should be protected, and should be respected. The world culture the overall concept should be the combination of a variety of the national culture, rather than one single culture of unify the whole country.

New folk music is more nationalization in general Chinese pop music, traditional music is more popularization, generated in the dual need is relying on the traditional and the folk music elements, reasonable use of western modern skills and create a form of music, it makes the Chinese pop music and traditional music has better development vision that is of great significance in the field of Chinese music of a transformation which is the west against the best example of western music hegemony.

Music culture is an integral part of culture system not only, and in the big culture system is one of the most active and the most distinctive cultural phenomenon. At the same time, the music culture is the most can represent a national essence and cultural characteristics of a form. As contact associated with cultural education, not only itself is a kind of cultural phenomenon and the carrier of culture, and is the inheritance, spread and development of the culture of the main and the most effective way. It can be said that without a culture not through education tradition and spread out. Especially in school education is the main base and a special place to spread culture, with its own set of system for the educatees influence, this form is also cannot match and replace any methods.

The Further Development of the Music. Music is closely connected with human life, which is widespread in the different historical periods and different society. Music is created, follow certain structure and rules that music is perception and appreciation which induce the listener's emotions. In the process of personal growth, uniqueness and universality of music played an important role.

In the process of communication, culture "home" and "global" highlights the problem of how to coordinate the relationship between the nature, the relationship between the processing result also directly affect the discrimination and conflict, instability and extremism human inevitably encounter many problems in the middle of the globalization process. The good news is that people in the music education theory research and practice to find the answer. In the western world, diversity of basic philosophy and social practice of multicultural music education provides a rich soil, and obtained a certain effect, but also for us to explore and implement the multicultural music education provided the beneficial train of thought and general experience [6-8].

Chinese national music, because of the greatness of the Chinese nation, is actually a female surface is very wide category, contains both Han Chinese music, also includes the music of ethnic minorities; Contains both traditional folk music, is also included with the historical development, social progress has changed the modern folk music and as long as it is, therefore, the creation of the Chinese nation, conform to the overall style of music works, Chinese music can be classified as Chinese folk music. This is a national feelings and political inclination toward the scientific research and rational thinking of internationalization of the general process of academic research and discipline construction. The development and transformation process in large part because music thoughts, ideas and methods of anthropology on Chinese scholar's vision, but also changes the subject category of academic ideas and concept extension, the academic paradigm and the method, which is formed by the adjustment and the perfection of which is the natural process of mature discipline. In practice, the national music as a unique branch of art, the content is rich and colorful, the peoples is the crystallization of art creation ability, 
occupies an important position in art education as is to perform the quality education, aesthetic and cultural artistic accomplishment education, appreciation contents and methods of irreplaceable.

Chinese music to the tune of the music time, tone, ti, music, love to relative positioning, flexible syntax, buildup its semantic features associated with flexible time and space structure model and the western music melody, music, works, spectrum, in music time, willing to "refers to the aspect of rigid positioning, syntax, fixed form is general rigorous, semantic cannot accumulate (like a fixed each performance, no detail and willing to change). The two kinds of differences as also can see that China's new music is influenced by western music syntax.

\section{Conclusion}

In this paper, we conduct research on the development trend of Chinese traditional music art from the perspectives of aesthetic and historical culture. In the process of the long history of human, which runs through music has always been, and each nation, because of the different history and the culture, geographical features, customs, the influence of such conditions is formed the different style, each has the national characteristic of national music. Chinese traditional music favor based on the principle of unity based in contrast, often in a way that is gradient performance contrast, natural, gentle change. Thousands of years of music heritage and development, accumulated a lot of varieties of music, form a unique artistic style. Complex and general diverse natural environment, broad and profound cultural background and the numerous national and population that make Chinese traditional music to become a complete, inheritance and fusion system. In the future research, we will combine more survey and the literature review to polish our current perspective.

\section{References}

[1] Mei, Yuxin. "The Houston Chinese Traditional Music Group: Negotiating Decades of Change in America." (2014).

[2] Chen, Gen-Fang, and Jia-Shing Sheu. "An optical music recognition system for traditional Chinese Kunqu Opera scores written in Gong-Che Notation." EURASIP Journal on Audio, Speech, and Music Processing 2014.1 (2014): 1-12.

[3] Xiaobing, He. "Which One is the Precondition: The Relationship between Disseminating and Inheriting of the Chinese Traditional Music." Journal of Nanjing Arts Institute (Music \& Performance) 1 (2014): 016.

[4] Lan, Z. H. O. N. G. "The Development History and Achievements of Chinese Traditional Instruments Department in Wuhan Conservatory of Music." Huangzhong (Journal of Wuhan Conservatory of Music, China) 4 (2013): 008.

[5] Shin, Hyunjoon, Yoshitaka Mōri, and Tunghung Ho. "Introduction: Special Issue-East Asian popular music and its (dis) contents." Popular Music 32.01 (2013): 1-5.

[6] LO, WAIHAN. "The music culture of older adults in Cantonese operatic singing lessons." Ageing and Society 35.08 (2015): 1614-1634.

[7] Xia, D. A. N. "Discussion on Reflection of Educational Value in Public Music Education of Normal Colleges." Higher Education of Social Science 8.3 (2015): 81-83.

[8] Cheung, Joys HY. "Riding the Wind With Mozart's 'Jupiter'Symphony: The Kantian and Daoist Sublimes in Chinese Musical Modernity." Music and Letters 96.4 (2015): 534-563. 